\title{
Additive effects of mean blood pressure and bilateral notching in the second trimester on subsequent angiogenesis-related factors
}

\author{
Chikako Hirashima ${ }^{1}$, Akihide Ohkuchi ${ }^{1}$, Kayo Takahashi ${ }^{1}$, Hirotada Suzuki ${ }^{1}$, Yoshio Matsuda ${ }^{2}$, \\ Shigeki Matsubara ${ }^{1}$ and Mitsuaki Suzuki ${ }^{1}$
}

It has not been clarified whether high mean blood pressure (HBP) of $\geqslant 90 \mathrm{~mm} \mathrm{Hg}$ and bilateral notching (BN) on uterine artery Doppler additively affect the subsequent circulating levels of placental growth factor (PIGF), soluble fms-like tyrosine kinase 1 (sFIt-1) and soluble endoglin (sEng). Serum levels of PIGF, sFlt-1 and sEng at 17-25 weeks and 26-32 weeks were measured in all women with HBP $+\mathrm{BN}-(n=272), \mathrm{HBP}-\mathrm{BN}+(n=130)$ and $\mathrm{HBP}+\mathrm{BN}+(n=60)$ in 1239 eligible women, and 338 consecutive women with HBP - BN - were selected from the remaining 777 women. Only data before the onset of preeclampsia were evaluated. The cutoff value of an abnormal decrease of PIGF was set at the 5th percentile, and those of an abnormal increase of sFIt-1, sFIt-1/PIGF and sEng were set at the 95th percentile. The frequency of HBP in those with BN - was almost the same as that in those with $\mathrm{BN}+(25.9 \%$ vs. $26.7 \%)$. In women with $\mathrm{HBP}-\mathrm{BN}-, \mathrm{HBP}-\mathrm{BN}+, \mathrm{HBP}+\mathrm{BN}-$ and $\mathrm{HBP}+\mathrm{BN}+$, the frequency of abnormal sFIt-1/PIGF ratio at $26-32$ weeks was $6.6 \%, 9.2 \%, 14.4 \%$ and $22.8 \%$, respectively; and the frequency of abnormal sFIt-1/PIGF ratio at 26-32 weeks in those with HBP + BN + was significantly increased than in HBP - BN - . Similarly, in the four groups, the frequency of abnormal sEng at $26-32$ weeks was $5.4 \%, 2.5 \%, 12.2 \%$ and $19.0 \%$, respectively; and the frequency in those with $\mathrm{HBP}+\mathrm{BN}+$ was significantly increased than in HBP $-\mathrm{BN}-$. In conclusion, high BP levels and abnormal uterine artery Doppler may be additively implicated in circulating abnormalities of angiogenesis-related factors.

Hypertension Research (2014) 37, 76-81; doi:10.1038/hr.2013.88; published online 15 August 2013

Keywords: bilateral notching; blood pressure levels; placental growth factor; soluble endoglin; soluble fms-like tyrosine kinase 1

\section{INTRODUCTION}

High blood pressure (HBP) and chronic hypertension are predictors of the occurrence of preeclampsia (PE). ${ }^{1-3}$ Bilateral notching $(\mathrm{BN})$, high resistance index, high pulsatility index (PI) or high notch depth index on the uterine artery Doppler (UAD) in the first and second trimesters are also predictors of PE. ${ }^{4-7}$ Both HBP and abnormal UAD in the second trimester were independent risk factors for $\mathrm{PE},{ }^{8-10}$ even in the first trimester. ${ }^{11}$ Abnormal increases in soluble fms-like tyrosine kinase 1 (sFlt-1) and soluble endoglin (sEng), accompanied by the decrease of placental growth factor (PlGF), are also implicated in the generation of PE. ${ }^{12-17}$ These increases are believed to be produced by placental hypoxia because of reduced perfusion, clinically represented as abnormal UAD. ${ }^{14}$ We showed that HBP, BN, plasma levels of the sFlt-1/PlGF ratio and plasma levels of hydroxysteroid (17- $\beta$ ) dehydrogenase 1 in the second trimester were independent risk factors for $\mathrm{PE} ;{ }^{17}$ and others also showed that HBP, high PI, decreased pregnancy-associated plasma protein-A and low PlGF levels in the first trimester were independent risk factors for not only early PE requiring delivery at $<34$ weeks but also late PE with delivery at $\geqslant 34$ weeks. $^{18}$

The original concept of the two-stage disorder of PE consists of the first stage of reduced placental perfusion followed by the second stage of maternal syndrome. ${ }^{19,20}$ It is plausible that the first stage is generated by the impairment of physiologic migration of trophoblasts into spiral arteries. ${ }^{14}$ However, it has been criticized because reduced perfusion, posited as secondary to failed remodeling of the maternal vessels supplying the intervillous space, is not sufficient to cause PE. ${ }^{20,21}$ In this research, we raised the hypothesis that HBP and $\mathrm{BN}$ in the second trimester might additively affect the frequencies of abnormal serum levels of sFlt-1, PlGF, sFlt-1/PlGF ratio and sEng in the second and early third trimesters.

Our aim was to evaluate the additive effects of HBP and BN in the second trimester on serum levels of sFlt-1, PlGF, sFlt-1/PlGF ratio and sEng in the second and early third trimesters in a prospective pregnant cohort, while stratifying the pregnant cohort into four groups using $\mathrm{HBP}$ and $\mathrm{BN}$.

${ }^{1}$ Department of Obstetrics and Gynecology, Jichi Medical University School of Medicine, Tochigi, Japan and 2Department of Obstetrics and Gynecology, Tokyo Women's Medical University, Tokyo, Japan

Correspondence: Dr A Ohkuchi, Department of Obstetrics and Gynecology, Jichi Medical University School of Medicine, Tochigi 329-0498, Japan. E-mail: okuchi@jichi.ac.jp

Received 6 May 2013; revised 29 May 2013; accepted 21 June 2013; published online 15 August 2013 


\section{METHODS}

\section{Subjects and procedures}

In April 2004, we started a prospective cohort study to make a prediction model of PE using maternal characteristics, BP levels, UAD waveforms and blood markers such as sFlt-1 and PlGF, after approval from the Ethics Committee of our institute. In the prospective cohort study, 1724 pregnant women gave written informed consent until October 2008 (Figure 1). Inclusion criteria were women with singleton pregnancy who sought routine antepartum maternal checkup at our tertiary perinatal center before 24 weeks of gestation. Exclusion criteria were women with multiple pregnancies, and those who sought an initial routine antepartum maternal checkup after 24 weeks of gestation. Blood pressure levels were measured at every maternal checkup. Blood pressure was measured with an Omron HEM-906 automated digital oscillometric sphygmanometer (OMRON Healthcare Japan, Kyoto, Japan), according to standard procedures. UAD was measured at 20-23 weeks of gestation, and BN and the mean PI (mPI) were surveyed. Blood samples were collected twice at 17-25 (mainly 20-23) and 26-32 (mainly 28-29) weeks of gestation. A total of 485 women were excluded from analysis because the UAD was measured only at $<16$ or $\geqslant 24$ weeks of gestation $(n=42)$, BP at 16-23 was not measured $(n=11)$, approval to sample blood could not obtained $(n=223)$, they delivered at another hospital because of 'Satogaeri bunben' (a traditional ritual (support system) for perinatal women in Japan; 'Satogaeri' means returning to the original family town or house and 'bunben' means delivery), the details of the clinical outcome were not available $(n=82)$ and $\mathrm{BN}$ at $20-23$ weeks was not evaluated $(n=127)$. We defined HBP + as a MBP at 16-23 weeks of $\geqslant 90 \mathrm{~mm} \mathrm{Hg}$, and defined BN + when notchings at 20-23 weeks were seen in both uterine artery flow velocity waveforms. In the remaining 1239 women, we selected women without either HBP or BN (HBP $-\mathrm{BN}-, n=338)$ in 800 consecutive pregnant subjects recruited early in this study, whereas we used all women with $\mathrm{HBP}$ but not $\mathrm{BN}(\mathrm{HBP}+\mathrm{BN}-$, $n=272)$, BN but not HBP (HBP $-\mathrm{BN}+, n=130)$ and both HBP and BN $(\mathrm{HBP}+\mathrm{BN}+, n=60)$. These data were used in previous reports. ${ }^{22}$

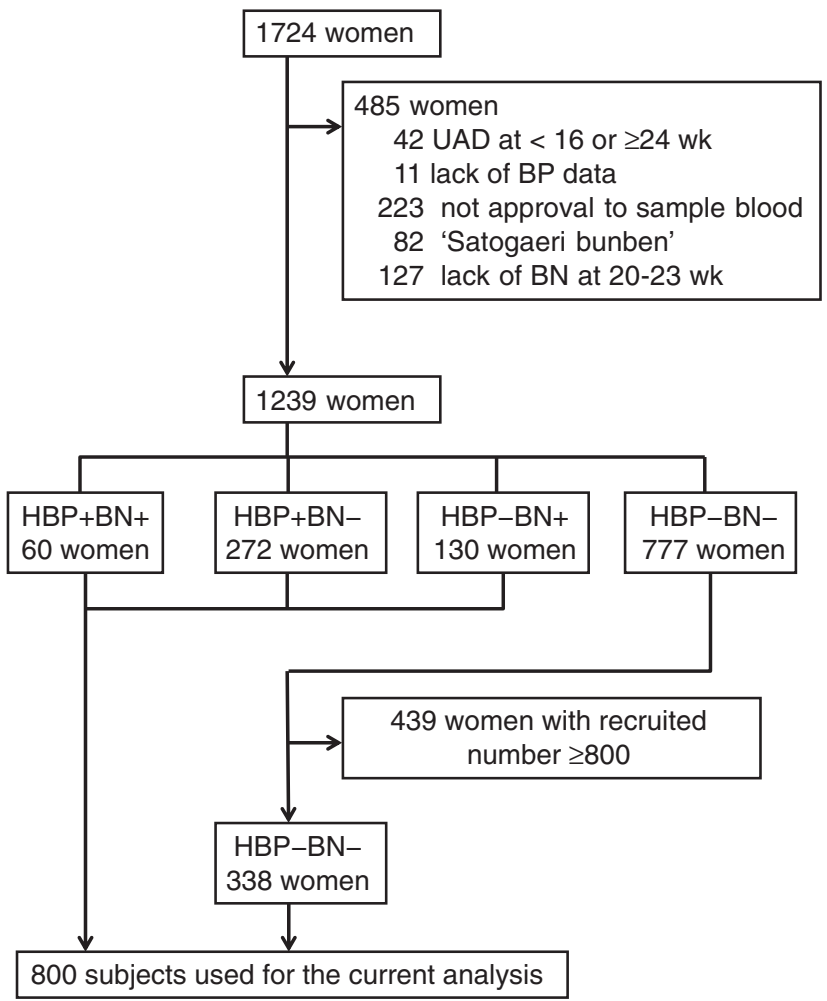

Figure 1 Patient exclusion and selection flowchart for the current analysis. $\mathrm{BN}$, bilateral notching; $\mathrm{BP}$, blood pressure; $\mathrm{HBP}$, high blood pressure; wk, weeks of gestation; UAD, uterine artery Doppler.
Serum samples were centrifuged at $4{ }^{\circ} \mathrm{C}$ at 2500 r.p.m. for $15 \mathrm{~min}$, and were stored at $-20^{\circ} \mathrm{C}$ until use. Enzyme-linked immunosorbent assays for human sFlt-1 (DVR100B; R\&D Systems, Minneapolis, MN, USA), PlGF (DPG00; R\&D Systems) and sEng (DNDG00; R\&D Systems) were performed with a single measurement according to the manufacturer's instructions. The minimal detectable doses in the assays for sFlt-1, PlGF and sEng were 3.5, 7 and $7 \mathrm{pg} \mathrm{ml}^{-1}$, respectively. The intraassay and interassay coefficients of variance for sFlt-1 were $2.6-3.8 \%$ and $5.5-9.8 \%$; those for PlGF were $3.6-7.0 \%$ and $10.9-11.8 \%$; and those for sEng were $2.8-3.2 \%$ and $6.3-6.7 \%$, respectively.

\section{Definition of cutoff values of sFlt-1, PlGF, sFlt-1/PlGF ratio and sEng}

The details of methods are included in the Supplementary Information. In brief, the cutoff value of sFlt-1, PlGF, sFlt-1/PlGF ratio and sEng at 17-25 weeks was set at $3577,157,12.3$ and $7.8 \mathrm{ng} \mathrm{m}^{-1}$, respectively; and cutoff value of each marker at 26-32 weeks was set at 3350, 233, 8.4 and $13.1 \mathrm{ng} \mathrm{ml}^{-1}$, respectively.

\section{Definitions of gestational hypertension (GH) and PE}

We defined GH and PE according to the definition and classification of pregnancy-induced hypertension (PIH) (2004) of the Japan Society for the Study of Hypertension in Pregnancy (JSSHP). ${ }^{23,24}$ In brief, PE was defined as hypertension with proteinuria occurring after week 20 of gestation but resolving by week 12 postpartum, whereas GH was defined as hypertension without proteinuria occurring after week 20 of gestation but resolving by week 12 postpartum. Hypertension was defined as systolic blood pressure $\geqslant 140 \mathrm{~mm} \mathrm{Hg}$ and/or diastolic blood pressure $\geqslant 90 \mathrm{~mm} \mathrm{Hg}$ on two occasions at least $4 \mathrm{~h}$ apart. Proteinuria was defined as $\geqslant 300 \mathrm{mg} \mathrm{day}^{-1}$ from $24 \mathrm{~h}$ urine collection. If only test tape was available, semiquantitative test results of $1+$ on 2 occasions at least 1 day apart were considered to constitute a positive result. Superimposed PE was defined as chronic hypertension diagnosed before pregnancy or before week 20 of gestation, with proteinuria emerging afterward. Superimposed PE was included in the category of PE in this study. All diagnoses of PE were decided by KT, who did not know the enzyme-linked ismmunosorbent assay results, and reviewed all the subjects' charts.

\section{Statistics}

The results are presented as the mean \pm s.d. In the current study, only data before the onset of PE were evaluated. Analysis of variance followed by Dunnett's method was used to compare continuous data in the four groups of $\mathrm{HBP}-\mathrm{BN}-, \mathrm{HBP}+\mathrm{BN}-, \mathrm{HBP}-\mathrm{BN}+$ and $\mathrm{HBP}+\mathrm{BN}+$, whereas $\mathrm{HBP}-$ $\mathrm{BN}$ - was set as the control. Statistical testing was conducted after logarithmic transformation for serum levels of sFlt-1, PlGF, the sFlt-1/PlGF ratio and sEng. Fisher's exact test followed by the Bonferroni method was used to compare categorical data. All analyses were performed using an IBM SPSS software package (version 21.0, IBM Japan, Tokyo, Japan). $P<0.05$ was considered significant.

\section{RESULTS}

The frequency of a past history of GH/PE in women with $\mathrm{HBP}+$ $\mathrm{BN}-, \mathrm{HBP}-\mathrm{BN}+$ and $\mathrm{HBP}+\mathrm{BN}+$ was significantly larger than in those with $\mathrm{HBP}-\mathrm{BN}-$ (controls) (Table 1 ). The frequency of obesity in women with $\mathrm{HBP}+\mathrm{BN}-$ and $\mathrm{HBP}+\mathrm{BN}+$ was significantly larger than in controls. All PE, PE with onset at $<36$ weeks, PE with onset at $<32$ weeks (early-onset $\mathrm{PE}$ ) and preterm delivery occurred more frequently in women with $\mathrm{HBP}+\mathrm{BN}+$ than in controls. Thus, women with $\mathrm{HBP}+\mathrm{BN}+$ were the highest-risk group for the occurrence of pregnancy-induced hypertension. In 530 women with recruitment numbers of $<801, \mathrm{MBP}$ at $16-23$ weeks was not significantly correlated with $\mathrm{mPI}$ at 20-23 weeks $(r=0.004$, $P=0.936)$; the frequency of $\mathrm{HBP}$ in those with $\mathrm{BN}-$ was almost the same as that in those with $\mathrm{BN}+(25.9 \%$ vs. $26.7 \%, P=0.902$, $n=561)$. 
Additive effect of HBP and BN on the abnormalities of angiogenesis-related factors

As for the frequencies of abnormal sFlt-1, PlGF, sFlt-1/PlGF ratio and sEng at 17-25 weeks, the frequency of abnormal sFlt-1 and abnormal sFlt-1/PlGF ratio was not significantly different among the four groups; the frequency of abnormal PlGF in women with $\mathrm{HBP}-$ $\mathrm{BN}-, \mathrm{HBP}+\mathrm{BN}-, \mathrm{HBP}-\mathrm{BN}+$ and $\mathrm{HBP}+\mathrm{BN}+$ was $3.8 \%, 6.7 \%$, $8.7 \%$ and $18.6 \%$, respectively, and the frequency of abnormal PlGF in those with $\mathrm{HBP}+\mathrm{BN}+$ was significantly increased than in those with $\mathrm{HBP}-\mathrm{BN}-$ (controls); and the frequency of abnormal sEng in the four groups was $5.0 \%, 7.1 \%, 10.2 \%$ and $22.0 \%$, respectively, and the frequency of abnormal sEng in those with $\mathrm{HBP}+\mathrm{BN}+$ was significantly higher than in controls (Figure 2a).

As for the frequencies of abnormal sFlt-1, PlGF, sFlt-1/PlGF ratio and sEng at 26-32 weeks, the frequency of abnormal sFlt-1 in women with $\mathrm{HBP}-\mathrm{BN}-, \mathrm{HBP}+\mathrm{BN}-, \mathrm{HBP}-\mathrm{BN}+$ and $\mathrm{HBP}+\mathrm{BN}+$ was

Table 1 Maternal and infantile characteristics according to the four classes defined by BN at 20-23 weeks and MBP at 16-23 weeks

\begin{tabular}{|c|c|c|c|c|c|c|}
\hline Characteristics & Missing values & $\begin{array}{c}H B P-B N- \\
(n=338)\end{array}$ & $\begin{array}{c}H B P+B N- \\
(n=272)\end{array}$ & $\begin{array}{c}H B P-B N+ \\
(n=130)\end{array}$ & $\begin{array}{c}H B P+B N+ \\
(n=60)\end{array}$ & P-value \\
\hline \multicolumn{7}{|l|}{ Women } \\
\hline Age (years) & 0 & $33.0 \pm 5.0$ & $33.7 \pm 4.9$ & $30.6 \pm 4.5$ & $31.5 \pm 4.6$ & $<0.001$ \\
\hline Nullipara (\%) & 0 & $153(45)$ & $136(50)$ & $73(56)$ & $33(55)$ & 0.140 \\
\hline Race: Japanese (\%) & 0 & $336(99.4)$ & $270(99.3)$ & $128(98.5)$ & $59(98.3)$ & 0.690 \\
\hline Family history of HT (\%) & 9 & $101(30)$ & $87(32)$ & $28(22)$ & $22(37)$ & 0.102 \\
\hline Past history of GH/PE (\%) & 1 & $7(2.1)$ & $17(6.3)$ & $12(9.3)$ & 7 (12) & 0.001 \\
\hline Current smoking (\%) & 40 & $12(3.8)$ & $15(6.0)$ & $3(2.3)$ & $4(6.7)$ & 0.294 \\
\hline $\mathrm{CH}(\%)$ & 0 & $0(0.0)$ & $19(7.0)$ & $0(0.0)$ & $9(15)$ & $<0.001$ \\
\hline Obesity (\%) & 2 & $27(8.0)$ & $125(46)$ & $11(8.5)$ & $27(45)$ & $<0.001$ \\
\hline Prepregnancy BMI $\left(\mathrm{kg} \mathrm{m}^{-2}\right)$ & 2 & $21.1 \pm 3.0$ & $25.5 \pm 5.3$ & $21.2 \pm 2.7$ & $25.7 \pm 5.4$ & $<0.001$ \\
\hline MBP at $16-23$ wk $(\mathrm{mm} \mathrm{Hg})$ & 0 & $79 \pm 7$ & $98 \pm 7$ & $80 \pm 6$ & $100 \pm 9$ & $<0.001$ \\
\hline $\mathrm{mPI}$ at $20-23 \mathrm{wk}$ & 35 & $0.97 \pm 0.26$ & $0.94 \pm 0.24$ & $1.35 \pm 0.38$ & $1.43 \pm 0.39$ & $<0.001$ \\
\hline PE (\%) & 0 & $3(0.9)$ & $15(5.5)$ & $5(3.8)$ & $11(18)$ & $<0.001$ \\
\hline PE with onset at $<36$ wk (\%) & 0 & $1(0.3)$ & $7(2.6)$ & $2(1.5)$ & $7(12)$ & $<0.001$ \\
\hline Early-onset PEa (\%) & 0 & $0(0.0)$ & $2(0.7)$ & $1(0.8)$ & $5(8.3)$ & $<0.001$ \\
\hline $\mathrm{GH}(\%)$ & 0 & $4(1.2)$ & $7(2.6)$ & $3(2.3)$ & $5(8.3)$ & 0.010 \\
\hline \multicolumn{7}{|l|}{ Infants } \\
\hline Gestational age at delivery (wk) & 0 & $38.8 \pm 1.9$ & $38.6 \pm 2.2$ & $38.7 \pm 3.4$ & $36.9 \pm 3.7$ & $<0.001$ \\
\hline Preterm delivery (\%) & 0 & $26(7.7)$ & $34(12.5)$ & $14(10.8)$ & $21(35.0)$ & $<0.001$ \\
\hline Infant birth weight (g) & 0 & $2948 \pm 441$ & $2986 \pm 562$ & $2810 \pm 477$ & $2429 \pm 760$ & $<0.001$ \\
\hline
\end{tabular}

Abbreviations: BMI, body mass index; BN, bilateral notching; $\mathrm{CH}$, chronic hypertension; GH, gestational hypertension; HBP, high blood pressure; HT, hypertension; MBP, mean blood pressure; $\mathrm{mPI}$, mean pulsatility index; $\mathrm{PE}$, preeclampsia; wk, weeks of gestation.

Data are shown as mean \pm s.d.

Bold fonts indicate group with significant differences of frequency or mean of the characteristics compared with $\mathrm{HBP}-\mathrm{BN}-$.

aEarly-onset PE was defined as PE with both onsets of hypertension and proteinuria at $<32$ weeks of gestation.

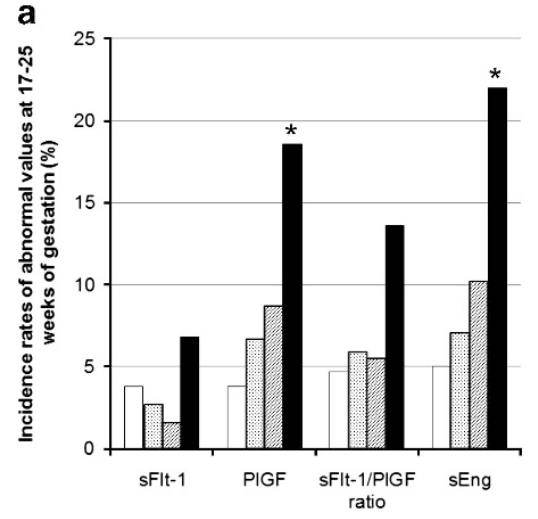

$\square \mathrm{HBP}-\mathrm{BN}-\square \mathrm{HBP}+\mathrm{BN}-\square \mathrm{HBP}-\mathrm{BN}+-\mathrm{HBP}+\mathrm{BN}+$

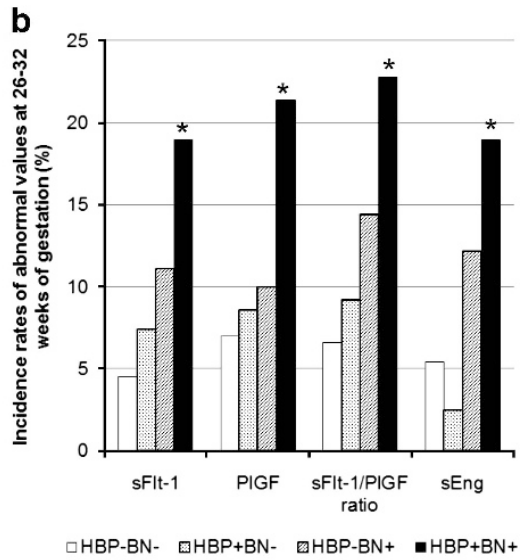

$\square$ HBP-BN- $\square \mathrm{HBP}+\mathrm{BN}-\square \mathrm{HBP}-\mathrm{BN}+\square \mathrm{HBP}+\mathrm{BN}+$

Figure 2 Frequencies of abnormal angiogenesis-related factors at 17-25 and 26-32 weeks of gestation in four classes defined by HBP and BN. Frequencies of abnormal sFIt-1, PIGF, sFIt-1/PIGF ratio and sEng at 17-25 weeks of gestation (a) and 26-32 weeks of gestation (b) in women with $\mathrm{HBP}-\mathrm{BN}-$ (clear bar), $\mathrm{HBP}+\mathrm{BN}-$ (dotted bar), $\mathrm{HBP}-\mathrm{BN}+$ (shaded bar) and HBP + BN + (black bar) in the second trimester are shown. The asterisk indicates that the frequency of abnormal values in the category is significantly higher than in the controls (women with HBP - BN -). The cutoff value of abnormal sFIt-1, sFIt-1/PIGF ratio and sEng was the 95th percentile of the respective normal reference range, and the cutoff value of abnormal PIGF was the 5th percentile of the normal reference range. BN, bilateral notching; HBP, high blood pressure; PIGF, placental growth factor; sEng, soluble endoglin; sFlt-1, soluble fms-like tyrosine kinase 1 ; wk, weeks of gestation. 
$4.5 \%, 7.4 \%, 11.1 \%$ and $19.0 \%$, respectively, and the frequency in those with $\mathrm{HBP}+\mathrm{BN}+$ was significantly increased than in controls; the frequency of abnormal PlGF in the four groups was $7.0 \%, 8.6 \%$, $10.0 \%$ and $21.4 \%$, respectively, and the frequency in those with $\mathrm{HBP}+\mathrm{BN}+$ was significantly increased than in controls; the frequency of abnormal sFlt-1/PlGF ratio in the four groups was $6.6 \%, 9.2 \%, 14.4 \%$ and $22.8 \%$, respectively, and the frequency in those with $\mathrm{HBP}+\mathrm{BN}+$ was significantly increased than in controls; and the frequency of abnormal sEng in the four groups was $5.4 \%$, $2.5 \%, 12.2 \%$ and $19.0 \%$, respectively, and the frequency in those with $\mathrm{HBP}+\mathrm{BN}+$ was significantly increased than in controls (Figure $2 \mathrm{~b}$ ).
The correlationship among MBP, mPI and angiogenesis-related factors

We evaluated the correlation coefficients among MBP at 16-23 weeks, $\mathrm{mPI}$ at 20-23 weeks and serum levels of sFlt-1, PlGF, sFlt-1/PlGF ratio and sEng at 17-25 and 26-32 weeks (Table 2). There was no correlation between $\mathrm{MBP}$ and $\mathrm{mPI}$. MBP was significantly correlated with sFlt-1, PlGF and sFlt-1/PlGF ratio at 17-25 weeks, and with sFlt-1, PlGF and sFlt1/PlGF ratio at 26-32 weeks; and mPI was significantly correlated with sFlt-1, PlGF and sEng at 17-25 weeks, and with sFlt-1, PlGF, sFlt-1/PlGF ratio and sEng at 26-32 weeks.

Table 2 The correlation coefficients among MBP at 16-23 wks, mPI at 20-23 wks and serum levels of $\log _{10}$ sFlt-1, $\log _{10}$ PIGF, $\log _{10}$ (sFIt-1/PIGF) and $\log _{10}$ sEng at $17-25$ and $26-32$ wks

\begin{tabular}{|c|c|c|c|c|c|c|c|c|c|c|}
\hline & \multirow[b]{3}{*}{$M B P$} & \multirow[b]{3}{*}{$m P I$} & \multicolumn{5}{|c|}{$\log _{10}$} & \multicolumn{3}{|c|}{$\log _{10}$} \\
\hline & & & $\log _{10} \mathrm{sFlt}-1$ & $\log _{10} P / G F$ & (sFlt-1/PIGF) & $\log _{10}$ SEng & $\log _{10} \mathrm{SFlt}-1$ & $\log _{10} P I G F$ & (sF/t-1/PIGF) & $\log _{10}$ SEng \\
\hline & & & at $17-25 w k s$ & at $17-25 w k s$ & at $17-25 w k s$ & at $17-25$ wks & at 26-32 wks & at 26-32 wks & at $26-32$ wks & at $26-32 w k s$ \\
\hline MBP & 1 & -0.018 & $0.076 *$ & $-0.160 * * *$ & $0.180 * * *$ & 0.045 & $0.129 * *$ & $-0.150 * * *$ & $0.189 * * *$ & 0.009 \\
\hline $\mathrm{mPI}$ & -0.018 & 1 & $-0.089 *$ & $-0.114^{* *}$ & 0.019 & $0.131^{* * *}$ & $0.108 *$ & $-0.140^{* *}$ & $0.168^{* * *}$ & $0.097 *$ \\
\hline $\log _{10}$ sFlt-1 at $17-25$ wks & $0.076 *$ & $-0.089 *$ & 1 & $0.150 * * *$ & $0.658 * * *$ & $0.286 * * *$ & $0.608 * * *$ & 0.080 & $0.339 * * *$ & $0.131 * *$ \\
\hline $\log _{10}$ PIGF at $17-25$ wks & $-0.160 * * *$ & $-0.114^{* *}$ & $0.150 * * *$ & 1 & $-0.646^{* * *}$ & 0.015 & -0.003 & $0.679 * * *$ & $-0.473^{* * *}$ & -0.056 \\
\hline $\begin{array}{l}\log _{10}(\mathrm{sFIt}-1 / \mathrm{PIGF}) \\
\text { at } 17-25 \text { wks }\end{array}$ & $0.180 * * *$ & 0.019 & $0.658 * * *$ & $-0.646^{* * *}$ & 1 & $0.210 * * *$ & $0.473^{* * *}$ & $-0.441^{* * *}$ & $0.612^{* * *}$ & $0.143^{* *}$ \\
\hline $\log _{10}$ sEng at $17-25$ wks & 0.046 & $0.131^{* * *}$ & $0.286 * * *$ & 0.015 & $0.210 * * *$ & 1 & $0.265^{* * *}$ & 0.001 & $0.172 * * *$ & $0.645 * * *$ \\
\hline $\log _{10}$ sFlt-1 at $26-32$ wks & $0.129 * *$ & $0.108 *$ & $0.608 * * *$ & -0.003 & $0.473^{* * *}$ & $0.265^{* * *}$ & 1 & $-0.097 *$ & $0.720 * * *$ & $0.456 * * *$ \\
\hline $\log _{10} \mathrm{PIGF}$ at $26-32$ wks & $-0.150 * * *$ & $-0.140^{* *}$ & 0.080 & $0.679 * * *$ & $-0.441^{* * *}$ & 0.001 & $-0.097^{*}$ & 1 & $-0.760 * * *$ & -0.078 \\
\hline $\begin{array}{l}\log _{10}(\mathrm{sFIt}-1 / \mathrm{PIGF}) \\
\text { at } 26-32 \text { wks }\end{array}$ & $0.189 * * *$ & * $0.168^{* * *}$ & $0.339 * * *$ & $-0.473^{* * *}$ & $0.612^{* * *}$ & $0.172^{* * *}$ & $0.720 * * *$ & $-0.760^{* * *}$ & 1 & $0.352^{* * *}$ \\
\hline $\log _{10}$ sEng at 26-32 wks & 0.009 & $0.097 *$ & $0.131 * *$ & -0.056 & $0.143^{* *}$ & $0.645^{* * *}$ & $0.456 * * *$ & -0.078 & $0.352 * * *$ & 1 \\
\hline
\end{tabular}

Abbreviations: MBP, mean blood pressure; mPI, mean pulsatility index; PIGF, placental growth factor; sEng, soluble endoglin; sFlt-1, soluble fms-like tyrosine kinase 1; wks, weeks of gestation. $* P<0.05 ; * * P<0.01 ;$ and $* * * P<0.001$
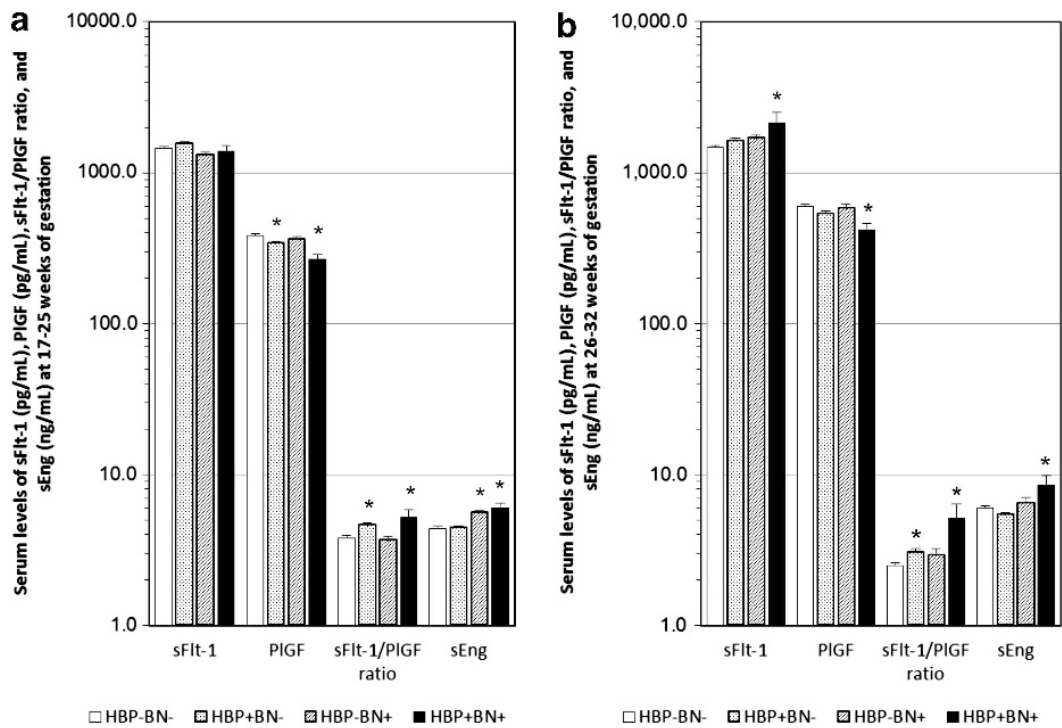

Figure 3 Serum levels of angiogenesis-related factors at 17-25 and 26-32 weeks of gestation in four classes defined by HBP and BN. Serum levels of sFIt-1, PIGF, sFIt-1/PIGF ratio and sEng at 17-25 weeks of gestation (a) and 26-32 weeks of gestation (b) in women with HBP - BN - (clear bar), $\mathrm{HBP}+\mathrm{BN}-$ (dotted bar), $\mathrm{HBP}-\mathrm{BN}+$ (shaded bar) and $\mathrm{HBP}+\mathrm{BN}+$ (black bar) in the second trimester are shown. The asterisk indicates that the serum level of angiogenesis-related factors in the category is significantly higher than in the controls (women with $\mathrm{HBP}-\mathrm{BN}-$ ). BN, bilateral notching; HBP, high blood pressure; PIGF, placental growth factor; sEng, soluble endoglin; sFlt-1, soluble fms-like tyrosine kinase 1; wk, weeks of gestation. 
The comparisons of raw values of sFlt-1, PlGF, sFlt-1/PlGF ratio and sEng

As for the serum levels of sFlt-1, PlGF, sFlt-1/PlGF ratio and sEng at 17-25 weeks, sFlt-1 was not significantly different among women with $\mathrm{HBP}-\mathrm{BN}-$ (controls), $\mathrm{HBP}+\mathrm{BN}-, \mathrm{HBP}-\mathrm{BN}+$ and $\mathrm{HBP}+$ $\mathrm{BN}+$; the levels of PlGF in those with $\mathrm{HBP}+\mathrm{BN}-$ and those with $\mathrm{HBP}+\mathrm{BN}+$ were significantly larger than in the controls; the levels of sFlt-1/PlGF ratio in those with $\mathrm{HBP}+\mathrm{BN}-$ and those with $\mathrm{HBP}+\mathrm{BN}+$ were significantly larger than in the controls; and the levels of sEng in those with $\mathrm{HBP}-\mathrm{BN}+$ and those with $\mathrm{HBP}+$ $\mathrm{BN}+$ were significantly larger than in the controls (Figure $3 \mathrm{a}$ ).

As for the serum levels of sFlt-1, PlGF, sFlt-1/PlGF ratio and sEng at 26-32 weeks, the level of sFlt-1 in those with $\mathrm{HBP}+\mathrm{BN}+$ was significantly larger than in the controls; the level of PlGF in those with $\mathrm{HBP}+\mathrm{BN}+$ was significantly larger than in the controls; the levels of sFlt-1/PlGF ratio in those with $\mathrm{HBP}+\mathrm{BN}-$ and those with $\mathrm{HBP}+$ $\mathrm{BN}+$ were significantly larger than in the control; and the level of sEng in those with $\mathrm{HBP}+\mathrm{BN}+$ was significantly larger than in the controls (Figure 3a).

\section{DISCUSSION}

In this study, we found the following novel findings. First, high MBP levels and $\mathrm{BN}$ were additively implicated in the appearances of abnormal PlGF and abnormal sEng at 17-25 weeks. Second, high MBP levels and BN were additively implicated in the appearances of not only abnormal PlGF and abnormal sEng but also abnormal sFlt-1 and abnormal sFlt-1/PlGF ratio at 26-32 weeks. These two findings suggested that a predisposition to hypertension and hypoperfusion to the placenta in the second trimester may additively interact to increase the release of antiangiogenic factors from the placenta into the maternal circulation, and may finally increase the probability of the later occurrence of PE.

Redman ${ }^{19}$ originally introduced the concept that PE may be a twostage disorder: the first stage is reduced placental perfusion that leads to the second stage, maternal syndrome. It has been believed that the first stage is generated by the impairment of physiologic migration of trophoblasts into spiral arteries, a phenomenon that is reflected by abnormal UAD in the first and second trimesters, such as BN, high resistance index, high PI or high notch depth index. ${ }^{4-6,17,18}$ However, it has been criticized because reduced perfusion, posited as secondary to failed remodeling of the maternal vessels supplying the intervillous space, is not sufficient to cause PE. ${ }^{20,21}$ Maternal constitutional factors such as genetic susceptibility, obesity, diabetes and diet might be necessary to interact with reduced placental perfusion to lead to $\mathrm{PE} ;^{20,21}$ or oxidative stress, endoplasmic reticulum stress and inflammatory stress might be necessary to interact with reduced placental perfusion to lead to overt PE. ${ }^{25}$ To the best of our knowledge, no researchers have proposed that not only impairment of the physiological migration of trophoblasts into the spiral arteries, but also increased blood pressure might affect the maternal vessels supplying the intervillous space, although Roberts and Hubel ${ }^{20}$ have proposed that maternal constitutional factors, such as genetic, obesity and diabetes, could also stimulate abnormal placentation. In our current research, we ascertained that $\mathrm{HBP}$ and $\mathrm{BN}$ in the second trimester additively affected the abnormal increases of sFlt-1 and sEng in the maternal circulation before the onset of $\mathrm{PE}$, suggesting that a predisposition to hypertension and hypoperfusion to the placenta in the second trimester may synergistically interact to increase the release of antiangiogenic factors from the placenta into the maternal circulation, and may finally increase the probability of the later occurrence of PE.
In conclusion, we found that in pregnant women with both HBP and $\mathrm{BN}$ in the second trimester, serum levels of sFlt-1/PlGF and sEng in the second and early third trimesters were significantly increased. However, we do not know why relatively high blood pressure induced the release of angiogenesis-related factors from the placenta into the maternal circulation. If maternal blood pressure is controlled more strictly, are the effects of HBP on the increase of angiogenesis-related factors lessened? The comparison of women with chronic hypertension with and without strict blood level controls might answer our question.

\section{CONFLICT OF INTEREST}

The authors declare no conflict of interest.

\section{ACKNOWLEDGEMENTS}

We thank Mr Sugimoto for kindly providing analyses of the database. This work was supported by Grants-in-Aid (18591809, 24390383 and 24592482 to AO) from the Ministry of Education, Culture, Sports, Science and Technology in Japan, and Research Grants (H20-Kodomo-Ippan-003 to YM) from the Japanese Ministry of Health, Labor, and Welfare.

1 Imasaki R, Ohkuchi A, Furuta I, Ojima T, Matsubara S, Sato I, Minakami H. Relationship between blood pressure level in early pregnancy and subsequent changes in blood pressure during pregnancy. Acta Obstet Gynecol Scand 2002; 81: 918-925.

2 Ohkuchi A, Iwasaki R, Suzuki H, Hirashima C, Takahashi K, Usui R, Matsubara S, Minakami H, Suzuki M. Normal and high-normal blood pressures, but not body mass index, are risk factors for the subsequent occurrence of both preeclampsia and gestational hypertension: a retrospective cohort study. Hypertens Res 2006; 29: 161-167.

3 North RA, McCowan LM, Dekker GA, Poston L, Chan EH, Stewart AW, Black MA, Taylor RS, Walker JJ, Baker PN, Kenny LC. Clinical risk prediction for pre-eclampsia in nulliparous women: development of model in international prospective cohort. BMJ 2011; 342: d1875.

4 Ohkuchi A, Minakami H, Sato I, Mori H, Nakano T, Tateno M. Predicting the risk of preeclampsia and a small-for-gestational-age infant by quantitative assessment of the diastolic notch in uterine artery flow velocity waveforms in unselected women. Ultrasound Obstet Gynecol 2000; 16: 171-178

5 Papageorghiou AT, Yu CK, Bindra R, Pandis G, Nicolaides KH. Fetal Medicine Foundation Second Trimester Screening Group. Multicenter screening for pre-eclampsia and fetal growth restriction by transvaginal uterine artery Doppler at 23 weeks of gestation. Ultrasound Obstet Gynecol 2001; 18: 441-449.

6 Cnossen JS, Morris RK, ter Riet G, Mol BW, van der Post JA, Coomarasamy A, Zwinderman AH, Robson SC, Bindels PJ, Kleijnen J, Khan KS. Use of uterine artery Doppler ultrasonography to predict pre-eclampsia and intrauterine growth restriction: a systematic review and bivariable meta-analysis. CMAJ 2008; 178: 701-711.

7 Takahashi K, Ohkuchi A, Hirashima C, Matsubara S, Suzuki M. Establishing reference values for mean notch depth index, pulsatility index and resistance index in the uterine artery at 16-23 weeks' gestation. J Obstet Gynaecol Res 2012; 38: 1275-1285.

8 Benedetto C, Valensise H, Marozio L, Giarola M, Massobrio M, Romanini C. A two-stage screening test for pregnancy-induced hypertension and preeclampsia. Obstet Gynecol 1998; 92: 1005-1011.

9 Rang S, van Montfrans GA, Wolf H. Serial hemodynamic measurement in normal pregnancy, preeclampsia, and intrauterine growth restriction. Am J Obstet Gynecol 2008; 198: e1-e9.

10 Onwudiwe N, Yu CK, Poon LC, Spiliopoulos I, Nicolaides KH. Prediction of preeclampsia by a combination of maternal history, uterine artery Doppler and mean arterial pressure. Ultrasound Obstet Gynecol 2008; 32: 877-883.

11 Poon LC, Karagiannis G, Leal A, Romero XC, Nicolaides KH. Hypertensive disorders in pregnancy: screening by uterine artery Doppler imaging and blood pressure at 11-13 weeks. Ultrasound Obstet Gynecol 2009; 34: 497-502.

12 Maynard SE, Min JY, Merchan J, Lim KH, Li J, Mondal S, Libermann TA, Morgan JP, Sellke FW, Stillman IE, Epstein FH, Sukhatme VP, Karumanchi SA. Excess placental soluble fms-like tyrosine kinase 1 (sFlt1) may contribute to endothelial dysfunction, hypertension, and proteinuria in preeclampsia. J Clin Invest 2003; 111: 649-658.

13 Venkatesha S, Toporsian M, Lam C, Hanai J, Mammoto T, Kim YM, Bdolah Y, Lim KH Yuan HT, Libermann TA, Stillman IE, Roberts D, D'Amore PA, Epstein FH, Sellke FW, Romero R, Sukhatme VP, Letarte M, Karumanchi SA. Soluble endoglin contributes to the pathogenesis of preeclampsia. Nat Med 2006; 12: 642-649.

14 Maynard SE, Karumanchi SA. Angiogenic factors and preeclampsia. Semin Nephrol $2011 ; 31: 33-46$.

15 Levine RJ, Maynard SE, Qian C, Lim KH, England LJ, Yu KF, Schisterman EF, Thadhani R, Sachs BP, Epstein FH, Sibai BM, Sukhatme VP, Karumanchi SA. Circulating angiogenic factors and the risk of preeclampsia. N Engl J Med 2004; 350: 672-683. 
16 Levine RJ, Lam C, Qian C, Yu KF, Maynard SE, Sachs BP, Sibai BM, Epstein FH, Romero R, Thadhani R, Karumanchi SA, CPEP Study Group. Soluble endoglin and other circulating antiangiogenic factors in preeclampsia. N Engl J Med 2006; 355 : 992-1005.

17 Ohkuchi A, Ishibashi O, Hirashima C, Takahashi K, Matsubara S, Takizawa T, Suzuki M. Plasma level of hydroxysteroid (17- $\beta$ ) dehydrogenase 1 in the second trimester is an independent risk factor for predicting preeclampsia after adjusting for the effects of mean blood pressure, bilateral notching and plasma level of soluble fms-like tyrosine kinase 1/placental growth factor ratio. Hypertens Res 2012; 35: 1152-1158.

18 Poon LC, Kametas NA, Maiz N, Akolekar R, Nicolaides KH. First-trimester prediction of hypertensive disorders in pregnancy. Hypertension 2009; 53: 812-818.

19 Redman CW. Current topic: pre-eclampsia and the placenta. Placenta 1991; 12 . 301-308.

20 Roberts JM, Hubel CA. The two stage model of preeclampsia: variations on the theme. Placenta 2009; 30 (Suppl A), S32-S37.
21 Roberts J. Pre-eclampsia a Two-Stage Disorder: What is the Linkage? Are There Directed Fetal/Placental Signals? In Lyall F, Belfort M (eds). Pre-eclampsia: Etiology and clinical practice. Cambridge University Press, New York, 2007, pp 183-194.

22 Ohkuchi A, Hirashima C, Matsubara S, Takahashi K, Matsuda Y, Suzuki M. Threshold of soluble fms-like tyrosine kinase 1/placental growth factor ratio for the imminent onset of preeclampsia. Hypertension 2011; 58: 859-866.

23 Sato K. A Proposal for a New Definition and Classification of "Pregnancy induced Hypertension (PIH)" (2004). in Japan Society for the Study of Toxemia of Pregnancy (ed): Historical Perspective of Study of Pregnancy-Induced Hypertension in Japan Tokyo, Medical View Co, 2005, pp 54-87.

24 Watanabe K, Naruse K, Tanaka K, Metoki H, Suzuki Y. Outline of definition and classification of "Pregnancy induced Hypertension (PIH)". Hypertens Res Pregnancy 2013; 1 : 3-4.

25 Redman CW, Sargent IL. Immunology of pre-eclampsia. Am J Reprod Immunol 2010; 63: $534-543$.

Supplementary Information accompanies the paper on Hypertension Research website (http://www.nature.com/hr) 